\title{
Effects of incorporating ampicillin, bile salts and carbohydrates in media on the recognition and selection of Aeromonas spp. from faeces
}

\author{
SUSAN V. WANT and S. E. MILLERSHIP
}

\section{Department of Bacteriology, Royal Postgraduate Medical School, Hammersmith Hospital, Du Cane Road, London W12 ONN}

Summary. The effects of incorporating ampicillin, some bile salts and sugars into media on the primary recognition and selection of aeromonads from faeces were examined. Most $(88 \%)$ of the 101 Aeromonas strains examined had an ampicillin MIC of $\geq 40 \mathrm{mg} / \mathrm{L}$, and would be isolated on blood agar containing ampicillin $30 \mathrm{mg} / \mathrm{L}$. The strains with an ampicillin MIC of $<40 \mathrm{mg} / \mathrm{L}$ were all of human origin and predominantly $A$. caviae. Although ampicillin at 10,20 or $30 \mathrm{mg} / \mathrm{L}$ in blood agar inhibited faecal bacteria, the ability to detect Aeromonas strains with a high ampicillin MIC was less when the lower concentrations of ampicillin were used, without any improvement in the isolation of those strains with a low ampicillin MIC. Thirtyseven strains were tested for sensitivity to several different bile salts and found to be at least as resistant to them as Escherichia coli NCTC 10418. Bile salt sensitivity was not related to the species or source of a strain. There were minor differences in sensitivity to bile salts between some strains which related to whether strains had been isolated originally in the presence of bile salt or not. The effects of the presence of E. coli, Klebsiella spp. and Enterococcus faecalis on the growth of Aeromonas strains in mixed culture on media with and without carbohydrate were examined. The colony size of some Aeromonas strains was reduced in mixed culture but colony counts were not affected with any Aeromonas strains. The effect of carbohydrate in the medium on Aeromonas colonies was apparent in the presence of other bacteria that fermented carbohydrate, when the non-fermenting Aeromonas colonies were often indistinguishable from those of the fermenters. When xylose was added to the medium the recognition of colonies of the non-fermenting aeromonads among those of other fermenting bacteria was difficult because their colonies were often of the same colour. This may explain the difficulty of isolating aeromonads from mixed cultures on some carbohydrate-containing media. It is recommended that if aeromonads are to be recognised in selective culture from faeces by their failure to ferment carbohydrate, a medium be used which inhibits the growth of non-aeromonad bacteria as much as possible.

\section{Introduction}

On MacConkey agar, or other media designed for the isolation of salmonellae and shigellae from faeces, Aeromonas colonies cannot always be distinguished easily from those of members of the Enterobacteriaceae. Therefore, several special selective or indicator media have been devised to facilitate their recognition and isolation. Most of these media contain one or more of ampicillin, bile salts and xylose. ${ }^{1,2,3}$ The first two are used as selective agents and the third with an indicator, to

Received 1 Aug. 1989; revised version accepted 2 Nov. 1989 distinguish xylose non-fermenting Aeromonas colonies from the xylose-fermenting organisms of the Enterobacteriaceae. However, some strains of Aeromonas may be inhibited by the ampicillin or bile salts. Strains vary in their resistance to ampicillin ${ }^{4}$ and some may be isolated only on media without bile salts. ${ }^{5}$ When carbohydrates are present, the recognition of aeromonads in mixed culture is much reduced. This has been attributed to the effects of carbohydrate metabolism by other genera. ${ }^{6}$ Therefore, we have evaluated the effects of incorporating these agents in media on the recognition and selection of aeromonads from faeces. 


\section{Materials and methods}

\section{Bacterial strains}

Aeromonas strains from faeces and water samples were isolated on xylose desoxycholate citrate agar or brilliant green bile salts agar as described previously. ${ }^{6,7}$ Strains from foods and other human sources were isolated on horse blood agar. Strains were identified to species level as described before. ${ }^{8}$

\section{Media}

Horse-blood agar was prepared by supplementing Columbia Agar Base (Oxoid, CM331) with sterile defibrinated horse blood (Tissue Culture Services) $5 \%$. Nutrient Broth was Oxoid (CM67) and Nutrient Agar was Oxoid (CM3). Media were sterilised by autoclaving at $121^{\circ} \mathrm{C}$ for $15 \mathrm{~min}$.

\section{Determination of ampicillin MIC for Aeromonas strains}

Ampicillin Adatabs ${ }^{\mathbb{B}}$ (Mast Laboratories) were dissolved in water and then diluted in Iso-Sensitest Broth (Oxoid, CM471) to make two-fold dilutions of ampicillin from 160 to $0 \cdot 1 \mathrm{mg} / \mathrm{L} ; 0 \cdot 1-\mathrm{ml}$ volumes of the dilutions of ampicillin (or Iso-sensitest broth alone as a control) were dispensed into wells of a microtitration plate. Bacterial inocula were made by adding to $10 \mathrm{ml}$ of Iso-sensitest broth $0.1 \mathrm{ml}$ of a suspension prepared by emulsifying four colonies from a blood-agar plate in $3 \mathrm{ml}$ of saline; a $0 \cdot 1-\mathrm{ml}$ volume of the inoculum $\left(c .10^{5} \mathrm{cfu} / \mathrm{ml}\right)$ was added to each well of the microtitration plate. Escherichia coli NCTC 10418 and the Oxford strain of Staphylococcus aureus, NCTC 6571, were used as control strains. Plates were incubated overnight at $37^{\circ} \mathrm{C}$ and then inspected for bacterial growth by eye. Each MIC determination was made twice.

\section{Effect of different concentrations of ampicillin on the isolation of aeromonads from faeces artificially inoculated with aeromonads}

Six strains of Aeromonas, representing those with a wide range of sensitivities to ampicillin, were incubated overnight at $37^{\circ} \mathrm{C}$ in nutrient broth and then serially diluted in 10 -fold steps in normal saline; $0 \cdot 1-\mathrm{ml}$ volumes of each dilution were added to $1 \mathrm{ml}$ of emulsified faeces $(10 \% \mathrm{w} / \mathrm{v}$ in normal saline). Aeromonas-inoculated faecal samples, and uninoculated faecal samples as controls, were mixed well and $0 \cdot 1-\mathrm{ml}$ volumes were subcultured on blood-agar plates containing ampicillin 10, 20 or $30 \mathrm{mg} / \mathrm{L}$ and on antibiotic-free medium. Inocula were spread in a standard way; there were two sets of outstreaks from the well each of four streaks, and a final single streak. The loop was flamed after each set of streaks. After incubation overnight at $37^{\circ} \mathrm{C}$, plates were flooded with oxidase reagent (tetramethyl-p-phenylene- diamine dihydrochloride $1 \% \mathrm{w} / \mathrm{v}$ in sodium thiosulphate $0.025 \% \mathrm{w} / \mathrm{v}$ ) and the relative number of oxidase-positive and -negative colonies was estimated. Numbers of colonies were scored on a semi-quantitative scale: $1=$ growth only in the "well" of the plate; $2=$ growth only in the first group of outstreaks; and so on. Oxidasepositive colonies were immediately subcultured on blood agar, and their identity as aeromonads was confirmed with Hugh and Leifson's O/F test and API 20E tests (API System S.A., La balme les Grottes, 38390 Montalieu Vercieu, France).

\section{Effect of bile salts on the growth of aeromonads}

Two groups of Aeromonas strains were examined; 23 strains whose primary isolation had been made on media containing bile salts, and 14 strains whose primary isolation was made on blood agar. E. coli NCTC 10418 was used as a control. Nutrient-agar plates were made containing a range of concentrations of different bile salts from 10 to $0 \cdot 1 \mathrm{~g} / \mathrm{L}$. The bile salts used were: Oxoid L55 and Difco; bile salts no. 3 (Oxoid L56 and Difco); sodium desoxycholate (Oxoid L57 and Difco); and sodium taurocholate (Difco). Nutrient-agar plates without bile salts were used as controls. A $0 \cdot 1-\mathrm{ml}$ inoculum from suspensions of $10^{7}, 10^{5}$ or $10^{2} \mathrm{cfu} / \mathrm{ml}$ of each strain was spread as a lawn over the plates.

\section{Effect of carbohydrate on the isolation of aeromonads from mixed cultures}

Four media were prepared; MacConkey Agar (Oxoid, CM7), and three media of similar formulation comprising (/L) peptone (Oxoid, L37) $20 \mathrm{~g}$, bile salts (Oxoid, L55) $5 \mathrm{~g}$, sodium chloride $5 \mathrm{~g}$, neutral red $0.075 \mathrm{~g}$, agar (Oxoid, L11) $12 \mathrm{~g}$ but in which lactose was either omitted or replaced by xylose (Oxoid, SR 22) $10 \mathrm{~g}$ or inositol (Sigma) $10 \mathrm{~g}$. Four strains of $\boldsymbol{A}$. sobria, four of $\boldsymbol{A}$. hydrophila and four of $A$. caviae, each species group having one strain found to ferment lactose on primary isolation, were selected. These strains and fresh isolates of $E$. coli, Klebsiella sp. and Enterococcus faecalis from faeces were incubated overnight at $37^{\circ} \mathrm{C}$ in nutrient broth. Viable counts of the pure cultures were made by the Miles and Misra technique ${ }^{9}$ on blood agar, MacConkey agar and bile salt medium without carbohydrate. Mixed cultures were prepared by mixing equal volumes of each pure Aeromonas culture with a culture of E. coli or Klebsiella or Ent. faecalis and viable counts were made on MacConkey agar and bile salt medium without carbohydrate. Viable counts of the same Aeromonas cultures, both before and after mixing with equal volumes of the $E$. coli broth culture, were also determined on bile salt medium containing xylose or inositol, or no carbohydrate, by spreading $0.1 \mathrm{ml}$ of the culture as a lawn over the whole of the plate. All plates were incubated overnight at $37^{\circ} \mathrm{C}$.

The Aeromonas colonies in mixed culture on plates with and without carbohydrate were recognised by flooding the plate with oxidase reagent. Their number in 
mixed cultures was compared with that from the pure cultures. If there was no inhibition, it would be expected that the counts of aeromonads in mixed cultures would approximate to half that of the pure culture on the same medium. Examination was also made for the effect of the presence of non-aeromonad bacteria on the size and colour of the Aeromonas colonies on the different media.

\section{Results}

Determination of the MIC of ampicillin for the Aeromonas isolates

A total of 101 Aeromonas strains comprising 68 from faeces, four from other human sources and 29 from food and water samples was tested. These included 24 strains of $A$. sobria of which 18 were from faeces, one from a blood culture, and five from water samples. There were also 18 strains of $A$. hydrophila, seven from faeces, two from other human sources, and nine from water samples, and 54 strains of $A$. caviae, 40 from faeces, one from a perineal swab, one from food and 12 from water samples. Five strains, three from faeces, and two from water could not be assigned to any of these species.

The MIC values of ampicillin for most $(88 \%)$ of the Aeromonas isolates were $\geq 40 \mathrm{mg} / \mathrm{L}$ (table I). However, nine strains $(9 \%)$, of which seven were A. caviae, had MIC values of $\leq 10 \mathrm{mg} / \mathrm{L}$. All strains with ampicillin MIC values of $<40 \mathrm{mg} / \mathrm{L}$ were of human origin.

Effect of different concentrations of ampicillin on the isolation of aeromonads from faeces artificially inoculated with aeromonads

All the six Aeromonas strains examined were isolated from human faeces. They included a strain of $A$. sobria with an ampicillin MIC of $\geq 80 \mathrm{mg} / \mathrm{L}$,

Table I. MICs of ampicillin for 101 Aeromonas strains

\begin{tabular}{|c|c|c|c|c|c|}
\hline \multirow[b]{2}{*}{$\begin{array}{c}\text { Ampicillin } \\
\mathrm{MIC}(\mathrm{mg} / \mathrm{L})\end{array}$} & \multicolumn{3}{|c|}{ Number of strains of } & \multirow[b]{2}{*}{ Other* } & \multirow[b]{2}{*}{ Total $(\%)$} \\
\hline & $\begin{array}{c}\text { A. sob- } \\
\text { ria }\end{array}$ & $\begin{array}{c}\text { A. hydro- } \\
\text { phila }\end{array}$ & $\begin{array}{c}\text { A. cav- } \\
\text { iae }\end{array}$ & & \\
\hline$\geq 80$ & 21 & 16 & 42 & 3 & $82(81)$ \\
\hline 40 & 2 & 2 & 3 & 0 & $7(7)$ \\
\hline 20 & 0 & 0 & 2 & 1 & $3(3)$ \\
\hline 10 & 1 & 0 & 4 & 1 & $6(6)$ \\
\hline 5 & 0 & 0 & 1 & 0 & $1(1)$ \\
\hline $2 \cdot 5$ & 0 & 0 & 2 & 0 & $2(2)$ \\
\hline
\end{tabular}

* Aeromonas strains not belonging to any recognised species. two strains of $A$. hydrophila with ampicillin MICs of $\geq 80$ and $40 \mathrm{mg} / \mathrm{L}$, and three strains of $A$. caviae with ampicillin MICs of 10,5 and $5 \mathrm{mg} / \mathrm{L}$ respectively.

All the concentrations of ampicillin used caused some reduction in the growth of the non-aeromonad bacteria. Plates without ampicillin had a score of 4 , those with ampicillin 10 and $20 \mathrm{mg} / \mathrm{L}$ scores of 3 , and those with ampicillin $30 \mathrm{mg} / \mathrm{L}$ gave scores of 2 . On plates without ampicillin and those with ampicillin $10 \mathrm{mg} / \mathrm{L}$, oxidase-positive colonies of the three strains with MIC values $\geq 40 \mathrm{mg} / \mathrm{L}$ could be detected at ratios of Aeromonas: non-Aeromonas bacteria of between $10: 1$ and $1: 100$. However, they were present only in the well of each plate. For the faecal samples inoculated with the strains of $A$. caviae with ampicillin MICs of either 10 or $5 \mathrm{mg} / \mathrm{L}$, no oxidase-positive colonies were detected on any plate containing ampicillin. This remained true even for samples containing 10 times more viable aeromonads than faecal bacteria. Ampicillin at 20 and $30 \mathrm{mg} / \mathrm{L}$ improved the isolation of the two strains with ampicillin MIC values $\geq 80 \mathrm{mg} / \mathrm{L}$, but only marginally improved the isolation of the strain with an ampicillin MIC of $40 \mathrm{mg} / \mathrm{L}$ (table II).

\section{Effect of bile salts on aeromonads}

The 37 strains examined included five strains of $A$. sobria, nine of $A$. hydrophila and 23 of $A$. caviae; 13 strains were from human faeces, three from foods and 21 from water samples. With an inoculum of $10^{2} \mathrm{cfu} / \mathrm{ml}$ neither the control $E$. coli strain nor most of the Aeromonas strains grew on any medium containing a bile salt at any concentration. Four Aeromonas strains (three of which were isolated originally on media containing bile salt) grew on media containing bile salts no. 3 (Difco) at a concentration of $\leq 2.5 \mathrm{~g} / \mathrm{L}$. Minor differences only were observed in the results with inocula of $10^{5}$ or $10^{7} \mathrm{cfu} / \mathrm{ml}$ and the latter was used routinely. The $E$. coli control strain was inhibited by bile salts (Difco) and sodium taurocholate (Difco) at concentrations of $10 \mathrm{~g} / \mathrm{L}$ and by all the other bile salt formulations tested at $2.5 \mathrm{~g} / \mathrm{L}$.

However, nearly all the 37 Aeromonas strains tested were more resistant to bile than the $E$. coli control irrespective of the type of bile salt used (table III). Sensitivity to bile salts did not appear to be influenced by the species or source of the strain and only minor differences in sensitivity to bile salts, which appeared to relate to the medium of original isolation of the strain, were observed. All the Aeromonas strains were inhibited by each bile salt tested at $10 \mathrm{~g} / \mathrm{L}$ but sodium taurocholate, which 
Table II. Recovery of Aeromonas strains from faeces artificially inoculated with aeromonads on blood agar containing different concentrations of ampicillin

\begin{tabular}{|c|c|c|c|c|c|c|c|c|c|c|}
\hline \multirow{3}{*}{$\begin{array}{c}\text { Concentration of } \\
\text { ampicillin }(\mathrm{mg} / \mathrm{L}) \\
\text { in } \\
\text { blood agar }\end{array}$} & \multicolumn{10}{|c|}{$\log _{10}$ of the ratio of the number of $\mathrm{cfu} / \mathrm{ml}$ of Aeromonas: faecal bacteria } \\
\hline & \multicolumn{2}{|c|}{$-1-<0$} & \multicolumn{2}{|c|}{$0-<1$} & \multicolumn{2}{|c|}{$1-<2$} & \multicolumn{2}{|c|}{$2-<3$} & \multicolumn{2}{|c|}{$3-<4$} \\
\hline & A & B & A & B & A & B & A & B & A & B \\
\hline 0 & - & NT & - & - & - & - & $\rightarrow$ & - & NT & - \\
\hline 10 & - & NT & - & - & - & - & - & - & NT & - \\
\hline 20 & + & NT & + & + & - & + & - & + & NT & $(+)$ \\
\hline 30 & + & NT & - & + & - & + & - & + & NT & + \\
\hline
\end{tabular}

+ Aeromonads isolated in all tests; $(+)$, aeromonads isolated in some tests; -, aeromonads not isolated in any test; NT, not tested.

A, results for a strain with an ampicillin MIC of $40 \mathrm{mg} / \mathrm{L}$; B, results for two strains with ampicillin MICs of $\geq 80 \mathrm{mg} / \mathrm{L}$.

was the least inhibitory of the bile salts, did not inhibit any strain at $\leq 5 \mathrm{~g} / \mathrm{L}$. However, Difco and Oxoid L55 bile salts inhibited nearly all strains at this concentration. All but five strains grew on media with all the bile salts at $\leq 2.5 \mathrm{~g} / \mathrm{L}$. These latter strains failed to grow in the presence of Difco bile salts at this concentration.

\section{Effect of carbohydrate on the detection of aeromonads in mixed culture}

The presence of Aeromonas strains had no effect

Table III. Inhibition of growth of Aeromonas strains by different bile salts in nutrient agar

\begin{tabular}{|c|c|c|c|c|c|c|}
\hline \multirow[b]{3}{*}{ Bile salt } & \multicolumn{6}{|c|}{$\begin{array}{l}\text { Cumulative percentage of strains } \\
\text { inhibited by bile salts at }\end{array}$} \\
\hline & \multicolumn{2}{|c|}{$2.5 \mathrm{~g} / \mathrm{L}$} & \multicolumn{2}{|c|}{$5 \mathrm{~g} / \mathrm{L}$} & \multicolumn{2}{|c|}{$10 \mathrm{~g} / \mathrm{L}$} \\
\hline & B & $\mathrm{N}$ & B & $N$ & B & $\mathrm{N}$ \\
\hline Oxoid L55 & 0 & 0 & 83 & 86 & 100 & 100 \\
\hline Difco & 4 & 29 & 95 & 100 & 100 & 100 \\
\hline Difco no. 3 & 0 & 0 & 9 & 50 & 100 & 100 \\
\hline Oxoid no. 3 L56 & 0 & 0 & 9 & 50 & 100 & 100 \\
\hline $\begin{array}{l}\text { Sodium desoxycholate } \\
\text { (Difco) }\end{array}$ & 0 & 0 & 9 & 7 & 100 & 100 \\
\hline $\begin{array}{l}\text { Sodium desoxycholate } \\
\text { (Oxoid L57) }\end{array}$ & 0 & 0 & 4 & 14 & 100 & 100 \\
\hline $\begin{array}{l}\text { Sodium taurocholate } \\
\text { (Difco) }\end{array}$ & 0 & 0 & 0 & 0 & 100 & 100 \\
\hline
\end{tabular}

B, strains isolated on primary isolation media with bile salts; numbers are percentages of a total of 23 .

$\mathrm{N}$, strains isolated on primary isolation media without bile salts; numbers are percentages of a total of 14 . on the count, size or colour of the colonies of E. coli, Klebsiella spp. or Ent. faecalis strains on any medium.

Mixed cultures of Aeromonas strains on MacConkey agar. Colony counts of 10 of the 12 Aeromonas strains in mixed culture with $E$. coli were within $10-10^{-1}$ of the expected number. Two strains each had counts of $10^{-1}-10^{-2}$ of the expected number. In mixed culture experiments with Klebsiella sp., viable counts of eight of the Aeromonas strains were within $10-10^{-1}$ of the expected number. Colony counts of the remaining four strains were difficult because the presence of colonies was obscured by capsular material produced by the Klebsiella sp. on all plates. In mixed culture experiments with Ent. faecalis, counts of all 12 Aeromonas strains were within $10-10^{-1}$ of the expected number. Two of the Aeromonas strains with counts $10-10^{-1}$ of the expected number produced smaller colonies in mixed culture with $E$. coli on MacConkey agar and medium without carbohydrate. One of these Aeromonas strains also behaved similarly in the presence of Klebsiella sp. and Ent. faecalis. On MacConkey agar, the colonies of two non-lactose fermenting strains of Aeromonas in mixed culture with $E$. coli or Klebsiella sp. were indistinguishable from lactose fermenters when no more than $0.5 \mathrm{~mm}$ from the periphery of a fermenting colony. More distant Aeromonas colonies were clearly non-lactose fermenting.

Mixed cultures of Aeromonas strains with E. coli on bile salt media with xylose or inositol. Counts of all 12 Aeromonas strains in mixed culture with $E$. coli were within $10-10^{-1}$ of the expected number on inositol- and on xylose-containing media. However, six of the 12 strains produced smaller colonies on media with inositol, xylose or no carbohydrate 
when in mixed culture. On inositol-containing media, all bacteria appeared to be non-fermenters but Aeromonas colonies were easily recognised after plates were flooded with oxidase reagent. With xylose-containing media, it was difficult or impossible to distinguish the non-xylose fermenting aeromonads from the xylose fermenting $E$. coli without using the oxidase reagent. Although the Aeromonas strains were clearly non-xylose fermenting in pure culture, they appeared to be fermenters in mixed culture.

\section{Discussion}

In primary media for the isolation of Aeromonas from faeces, the concentration of ampicillin used has usually been $10-30 \mathrm{mg} / \mathrm{L} .^{1,2,3,5}$ Most $(88 \%)$ of the 101 strains of Aeromonas we have tested had ampicillin MIC values of $\geq 40 \mathrm{mg} / \mathrm{L}$, and should be detected in the presence of $30 \mathrm{mg} / \mathrm{L}$, but $12 \%$ of the strains would have failed to grow. Even on media containing ampicillin $10 \mathrm{mg} / \mathrm{L}, 9 \%$ of the strains would not have grown. However, the incorporation of ampicillin into media was useful in suppressing the growth of non-aeromonad faecal bacteria. Any $\beta$-lactamase production by these bacteria did not appear to change significantly the MIC of ampicillin for aeromonads in mixed culture.

The selectivity of media containing ampicillin $10 \mathrm{mg} / \mathrm{L}$ for aeromonads was little better than that of blood agar without ampicillin. If ampicillin is used as a selective agent, we recommend that it be incorporated into media at a concentration of $30 \mathrm{mg} / \mathrm{L}$. Such a concentration may prevent the growth of some $A$. caviae strains but this might not be important because the pathogenicity of $A$. caviae is uncertain. ${ }^{10}$ It is of interest that all strains with an ampicillin MIC of $<40 \mathrm{mg} / \mathrm{L}$ were of human

\section{REFERENCES}

1. Kelly M T, Stroh E M D, Jessop J. Comparison of blood agar, ampicillin blood agar, MacConkey-ampicillintween-agar, and modified cefsulodin-irgasan-novobiocin agar for isolation of Aeromonas spp. from stool specimens. J Clin Microbiol 1988; 26: 1738-1740.

2. Von Graevenitz A, Bucher C. Evaluation of differential and selective media for isolation of Aeromonas and Plesiomonas spp. from human feces. J Clin Microbiol 1983; 17: $16-21$

3. Price E H, Hunt G H, Patel U, Walker-Smith J A. Aeromonas spp. in diarrhoea. Br Med J 1984; 289 : 1380. origin. However, many more strains from water should be tested to assess the significance of this finding.

All the 37 Aeromonas strains tested by us were inhibited by bile salt at concentrations equal to or greater than those required to inhibit the control $E$. coli NCTC 10418. The bile salt concentrations required for inhibition of Aeromonas strains at the higher inocula were between five and 10 times the concentrations normally used. The reported failure of some Aeromonas strains to grow on bile salts ${ }^{5}$ may be related to the incorporation of carbohydrates in the media used.

Although the presence of other bacteria reduced the colony size of some Aeromonas strains when growing in mixed culture, this inhibition was independent of the presence of carbohydrate in the medium. The apparent failure of some Aeromonas strains to grow in the presence of a Klebsiella sp. was the outcome of klebsiella capsular material obscuring underlying Aeromonas colonies.

Whenever large numbers of fermenting bacteria were present in mixed cultures on media containing carbohydrates, the nearby colonies of Aeromonas often also appeared to be fermenters. The effect was more obvious when colony counts were performed by spreading the inoculum over the whole plate. Moreover, if sufficient acid is produced in the medium the oxidase test may be falsely negative. ${ }^{11}$ If carbohydrates are to be used in a primary isolation medium to reveal non-fermenting aeromonads, our results suggest that it is desirable to suppress the growth of fermenting bacteria as much as possible. This may be the reason why xylose desoxycholate citrate (XDCA) agar is successful in aeromonad isolation, whereas less inhibitory media are effective only when there is either no carbohydrate present, or the contaminating flora does not ferment that present in the medium. ${ }^{2.6,12}$
4. Richardson C J L, Robinson J O, Wagener L B, Burke V. In vitro susceptibility of Aeromonas spp. to antimicrobial agents. J Antimicrob Chemother 1982; 9: 267-274.

5. Gracey M, Burke V, Robinson J. Aeromonas-associated gastroenteritis. Lancet 1982; 2 : 1304-1306.

6. Millership S E, Chattopadhyay B. Methods for the isolation of Aeromonas hydrophila and Plesiomonas shigelloides from faeces. J Hyg (Lond) 1984 ; 92 : 145-152.

7. Millership S E, Chattopadhyay B. Aeromonas hydrophila in chlorinated water supplies. J Hosp Infect 1985; 6: 7580.

8. Barer M R, Millership S E, Tabaqchali S. Relationship of toxin production to species in the genus Aeromonas. $J$ Med Microbiol 1986; 22: 303-309. 
9. Stokes E J, Ridgway G L. Clinical bacteriology, 5th edn, Ch. 10: Media testing and other techniques. London, Arnold. 1980 : $342-381$.

10. Millership S E, Barer M R, Tabaqchali S. Toxin production by Aeromonas spp. from different sources. $\mathrm{J} \mathrm{Med}$ Microbiol 1986; 22: 311-314.
11. Hunt L K, Overman T L, Otero R B. Role of $\mathrm{pH}$ in oxidase variability of Aeromonas hydrophila. J Clin Microbiol $1981 ; 13$ : 1054-1059.

12. Shread P, Donovan T J, Lee J V. A survey of the incidence of Aeromonas in human faeces. Soc Gen Microbiol $Q$ $1981 ; 8: 184$. 